\title{
Dieter Oelschlägel gestorben
}

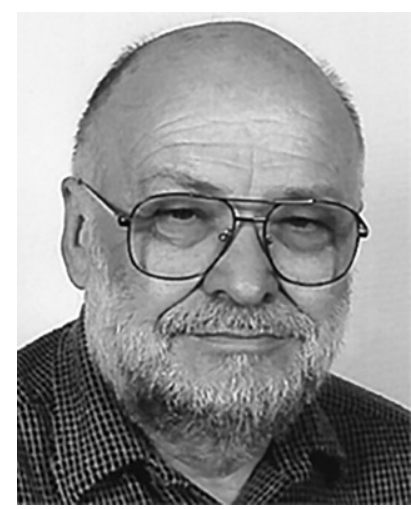

Portrait Dieter Oelschlägel

(Privatbesitz)

Dieter Oelschlägel wurde am 13. Januar 1939 in Chemnitz geboren und ist in einer streng pietistischen Familie aufgewachsen. Seine Eltern hätten es gern gesehen, wenn er Pastor oder Arzt geworden wäre - am besten „eine Art Albert Schweitzer“. Nach einem abgebrochenen Medizinstudium und einigen Jahren als Pfleger in der Psychiatrie entschloss er sich aber dazu, Pädagogik zu studieren. In dieser Zeit engagierte er sich hochschulpolitisch und war über Jahre hinweg AStA-Vorsitzender an der $\mathrm{PH}$ Berlin und Mitglied zahlreicher Aktionsgruppen der Studentenbewegung. Nicht zuletzt durch den Einfluss C.W. Müllers, dessen Assistent er wurde, wandte er sich zunehmend Themen der Sozialen Arbeit zu - vor allem der Gemeinwesensarbeit. Hier übernahm er eine Schlüsselrolle in der Entwicklung von Theorie und Praxis der GWA in Detschland.

Nach Stationen im Berliner Stadtteil-Projekt „Heerstraße Nord“ und im „Modellversuch soziale Studiengänge “ an der Gesamthochschule Kassel wurde er 1981 an die Universität Duisburg berufen, wo er bis Ende des Wintersemesters 2003/04 forschte und lehrte. Im anschließenden Ruhestand hat er nicht nur seine historischen Forschungen zum jüdischen Volksheim in Berlin wieder aufgenommen, sondern für die Grünen auch aktiv Kommunalpolitik an seinem Wohnort Dinslaken betrieben.

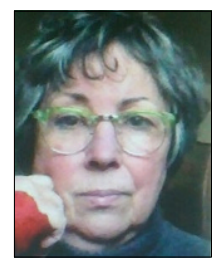

Bis Ende der 1990er Jahre war er auch im Sozial-ExtraBeirat aktiv. Wir werden ihn vermissen, seine Liebenswürdigkeit, seinen Witz, die Schärfe seines kritischen Denkens und sein Angebot, auch nach grundsätzlichen Auseinandersetzungen, auf der Stelle „ein fürchterliches Bier" zusammen trinken zu gehen.

Nach langen Jahren der Krankheit, die er mutig durchgestanden hat, nahm Dieter Oelschlägel am 10. März 2019 von uns Abschied. Die vielen Menschen, die ihm nahe gestanden haben, tröstet mit Sicherheit noch immer das Gefühl, ihn an ihrer Seite zu wissen, weil sie ihn so geliebt und verehrt haben.

\section{Sabine Hering}

